\title{
A New Regression Based Model for Estimation of the Process Parameters Affect for Texturing of Polyethylene Terephthalate (PET) Yarn
}

\author{
Kenan Yildirim, Suna Cetin, and Yusuf Ulcay
}

\begin{abstract}
This study comprises investigations of the effect of false-twist texturing process parameters onto the properties of PET (polyethylene terephthalate) yarn and performing prediction equations based on a non-linear regression mathematical model. The effect of texturing parameters on the properties of PET filaments was characterized through measurements of boiling water shrinkage, shrinkage force, crimp stability and crimp contraction. The properties of the textured yarn can be altered by changing of mainly three parameters which are $D / Y$ ratio, draw ratio and first heater temperature. Yarn samples were produced in three different levels of each of selected parameters and tested. In order to obtain empirical formulas for predicting the change of textured PET yarn properties with respect to selected production parameters, the yarns were produced in 27 different combinations. The starting point of the empirical equation is based on a completely randomized variance analyses model. The coefficients of the curves fitted were computed by means of non-linear regression analysis. $R^{2}$ values for these curves were observed to be highly reliable being about 0.85 .
\end{abstract}

Index Terms-PET yarn, fals-twist texturing factors, physical and performance parameters, regression-based mathematical model.

\section{INTRODUCTION}

One of the main disadvantages of man-made fibers is the flat geometry and smooth surface. The fiber waviness or crimp increases volume, resilience, moisture absorption, etc. Texturing methods have been developed to overcome this problem. Texturing is a common commercial process which gives crimp to the flat yarns. Among the several texturing methods, false twist texturing is the most favored method. False-twist texturing process is composed of four main steps, heating the thermoplastic fibers above the glass transition temperature ( $\mathrm{Tg}$ ), twisting, cooling the fibers below $\mathrm{Tg}$ and untwisting. Heater parameters, mainly heater temperature and residence time, together with fiber thermal properties influence textured yarn properties such as tenacity, crimp rigidity, dyeability, etc. [1]-[6].

False-twist texturing process can be investigated based on three main parameters, which are called $3 \mathrm{t}$ : tension, twist, and temperature [2], [7]. Draw ratio, D/Y ratio, and heater

Manuscript received January 9, 2015; revised March 28, 2015.

Kenan Yildirim is with the Bursa Technical University, Turkey (e-mail: kenan.yildirim@btu.edu.tr).

Suna Cetin is with the University of Kirıkkale, Turkey (e-mail: scetin@kku.edu.tr).

Yusuf Ulcay is with the Uludag University, Turkey (e-mail: ulcay@uludag.edu.tr). temperatures are the main process parameters to change $3 \mathrm{t}$ The ratio of the disk surface speed to the yarn speed is usually referred to as $D / Y$ ratio. $D / Y$ ratio is calculated as follows:

$$
\frac{D}{Y}=\frac{\text { circumferential } \text { speed of disks }(\mathrm{m} / \mathrm{min})}{\text { throughput } \text { speed of yarn }(\mathrm{m} / \mathrm{min})}
$$

If $\mathrm{D} / \mathrm{Y}$ ratio is low, the yarn tension before twisting unit will be low and the tension after the twisting unit will be high [8]-[11]. This situation can cause yarn damages. Draw ratio is the ratio of center shaft speed to the input shaft speed and is calculated as follows:

$$
\text { Draw Ratio }=\begin{array}{cccc}
\text { center } & \text { speed } & \text { shaft } & (\mathrm{m} / \mathrm{min}) \\
\text { input } & \text { speed } & \text { shaft } & (\mathrm{m} / \mathrm{min})
\end{array}
$$

Yildirim K. and coworkers used regression-based mathematical model for prediction poly oriented yarn (POY) PET yarn properties according to process parameters. The equation of this model was similar to a completely randomized variance analysis model. They used this model for prediction POY PET yarn properties according to process parameters in terms of tensile strength, tensile strain, draw force, crystallinity degree, K/S, brightness and boiling water shrinkage. They claimed that $R^{2}$ and r values showed that the equations are well-suited to predicting PET POY yarn properties for selected production parameters [12].

A. Majumdar and co-workers used linear regression model for estimation of rotor spun yarn breaking elongation beside other prediction methods of neural network and neuro-fuzzy. While their model includes parameters which affect yarn breaking elongation omitting parameter interactions, the model in this work includes both influence parameters and interactions of these parameters. According to A. Majumdar and co-workers' results, all of three prediction models give reasonable results with high accuracy. However, the error term is less in regression model than the others but standard deviation is higher [13].

J. Carey and co-workers used simple regression-based model as an alternative to existing models, which are finite element analysis, fabric geometry model and modified classical laminate plate theory, to eliminate the complexity and impractical use in industrial design for open mesh braided/woven fabrics [14].

Sular and Okur used simple regression model to predict total fabric handle with a minimum number of parameters. They used objective measurement results which are tensile, bending, shear, compression and surface properties, and 
pulling through a nozzle test, to predict subjective fabric handle. They used linear and log linear equations and claimed that very good result was obtained within the $R^{2}=0.88$ [15].

Park and co-workers used regression equation to estimate holding power and pressure sensation utilizing average pressure and pressure distribution, and constructed the regression equation to estimate Comfortable fittability index using the calculated pressure sensation. They defined comfortable fittability index and holding power to represent the subjective wearing comfort of caps. Using this model they developed a tool to measure comfort and holding power of a baseball cap from measuring the pressure inside caps [16].

TABLE I: TEXTURED PET YARN PROPERTIES [19]

\begin{tabular}{|c|c|c|c|c|c|c|c|c|c|}
\hline First heater temperature (0C) & 150 & & & & & & & & \\
\hline $\mathrm{D} / \mathrm{Y}$ ratio & 1.5 & & & 2.0 & & & 2.5 & & \\
\hline Draw ratio & 1.55 & 1.60 & 1.65 & 1.55 & 1.60 & 1.65 & 1.55 & 1.60 & 1.65 \\
\hline Crimp contraction $(\%)$ & 4.78 & 5.00 & 5.43 & 7.76 & 6.77 & 6.40 & 6.75 & 6.82 & 5.91 \\
\hline Std. Deviation & 0.03 & 0.49 & 0.28 & 0.99 & 0.18 & 0.09 & 0.39 & 0.32 & 0.26 \\
\hline Crimp stability (\%) & 76.38 & 77.24 & 77.37 & 75.04 & 74.98 & 75.52 & 73.78 & 74.54 & 74.08 \\
\hline Std. Deviation & 1.17 & 1.11 & 2.50 & 1.32 & 1.46 & 1.59 & 0.73 & 1.41 & 1.34 \\
\hline Boiling water shrinkage (\%) & 3.25 & 3.29 & 3.32 & 2.85 & 2.98 & 3.15 & 3.02 & 3.22 & 3.00 \\
\hline Std. Deviation & 0.12 & 0.11 & 0.11 & 0.08 & 0.08 & 0.10 & 0.06 & 0.07 & 0.08 \\
\hline Shrinkage force $(\mathrm{cN})$ & 6.31 & 7.20 & 8.03 & 5.93 & 6.80 & 7.51 & 5.84 & 6.69 & 7.41 \\
\hline Std. Deviation & 0.22 & 0.16 & 0.14 & 0.18 & 0.19 & 0.25 & 0.13 & 0.21 & 0.16 \\
\hline First heater temperature $\left({ }^{0} \mathrm{C}\right)$ & 190 & & & & & & & & \\
\hline $\mathrm{D} / \mathrm{Y}$ ratio & 1.5 & & & 2.0 & & & 2.5 & & \\
\hline Draw ratio & 1.55 & 1.60 & 1.65 & 1.55 & 1.60 & 1.65 & 1.55 & 1.60 & 1.65 \\
\hline Crimp contraction $(\%)$ & 12.13 & 13.63 & 10.45 & 13.43 & 12.82 & 11.83 & 12.00 & 11.98 & 10.89 \\
\hline Std. Deviation & 0.19 & 0.20 & 0.61 & 1.50 & 0.46 & 0.54 & 0.34 & 0.25 & 0.54 \\
\hline Crimp stability (\%) & 81.88 & 84.12 & 82.23 & 80.74 & 81.68 & 81.73 & 77.71 & 78.67 & 78.78 \\
\hline Std. Deviation & 0.79 & 0.38 & 0.38 & 1.00 & 0.38 & 0.53 & 0.45 & 0.82 & 0.71 \\
\hline Boiling water shrinkage (\%) & 2.06 & 1.94 & 1.92 & 1.72 & 1.75 & 1.83 & 1.69 & 1.72 & 1.83 \\
\hline Std. Deviation & 0.03 & 0.04 & 0.09 & 0.07 & 0.07 & 0.05 & 0.08 & 0.04 & 0.04 \\
\hline Shrinkage force $(\mathrm{cN})$ & 4.10 & 4.26 & 5.30 & 3.11 & 3.80 & 4.80 & 2.93 & 3.54 & 4.39 \\
\hline Std. Deviation & 0.19 & 0.14 & 0.30 & 0.19 & 0.19 & 0.15 & 0.14 & 0.20 & 0.23 \\
\hline First heater temperature $\left({ }^{0} \mathrm{C}\right)$ & 230 & & & & & & & & \\
\hline $\mathrm{D} / \mathrm{Y}$ ratio & 1.5 & & & 2.0 & & & 2.5 & & \\
\hline Draw ratio & 1.55 & 1.60 & 1.65 & 1.55 & 1.60 & 1.65 & 1.55 & 1.60 & 1.65 \\
\hline Crimp contraction $(\%)$ & 18.13 & 18.77 & 16.49 & 17.50 & 18.07 & 17.36 & 17.76 & 17.29 & 18.28 \\
\hline Std. Deviation & 0.53 & 2.78 & 0.75 & 0.70 & 0.43 & 0.41 & 0.83 & 0.74 & 2.10 \\
\hline Crimp stability (\%) & 80.28 & 82.73 & 82.38 & 78.61 & 80.84 & 81.52 & 79.02 & 80.81 & 81.49 \\
\hline Std. Deviation & 0.94 & 1.87 & 0.66 & 1.47 & 0.48 & 0.62 & 0.49 & 0.66 & 0.90 \\
\hline Boiling water shrinkage (\%) & 1.60 & 1.60 & 1.62 & 1.53 & 1.53 & 1.52 & 1.32 & 1.29 & 1.51 \\
\hline Std. Deviation & 0.14 & 0.03 & 0.08 & 0.06 & 0.05 & 0.04 & 0.09 & 0.04 & 0.04 \\
\hline Shrinkage force $(\mathrm{cN})$ & 1.11 & 1.28 & 1.45 & 1.02 & 1.13 & 1.17 & 0.96 & 1.05 & 1.18 \\
\hline Std. Deviation & 0.04 & 0.05 & 0.06 & 0.03 & 0.04 & 0.03 & 0.04 & 0.04 & 0.05 \\
\hline
\end{tabular}

TABLE II: THE ASSESSMENT OF PREDICTION CAPACITY OF MODEL

\begin{tabular}{|c|c|c|c|c|c|c|c|c|c|c|}
\hline Independent variable & $\begin{array}{l}\text { Predicted } \\
\text { value1 }\end{array}$ & $\begin{array}{l}\text { Actual } \\
\text { value1 }\end{array}$ & $\begin{array}{l}\text { Predicted } \\
\text { value2 }\end{array}$ & $\begin{array}{l}\text { Actual } \\
\text { value2 }\end{array}$ & $\begin{array}{l}\text { Predicted } \\
\text { value3 }\end{array}$ & $\begin{array}{l}\text { Actual } \\
\text { value3 }\end{array}$ & $\begin{array}{l}\text { Predicted } \\
\text { value4 }\end{array}$ & $\begin{array}{l}\text { Actual } \\
\text { value4 }\end{array}$ & $\begin{array}{l}\text { Predicted } \\
\text { value5 }\end{array}$ & $\begin{array}{l}\text { Actual } \\
\text { value5 }\end{array}$ \\
\hline $\begin{array}{l}\text { First heater } \\
\text { temperature }\left({ }^{0} \mathrm{C}\right)\end{array}$ & 190 & & 220 & & 200 & & 210 & & 205 & \\
\hline$D / Y$ ratio & 2 & & 2.5 & & 2.0 & & 1.5 & & 1.5 & \\
\hline Draw ratio & 1.55 & & 1.60 & & 1.65 & & 1.55 & & 1.60 & \\
\hline \multicolumn{11}{|l|}{ Dependent variable } \\
\hline $\begin{array}{l}\text { Crimp contraction } \\
(\%)\end{array}$ & 12.42 & 13.43 & 16.34 & 16.2 & 13.20 & 13.50 & 15.50 & 15.3 & 14.18 & 16 \\
\hline Crimp stability (\%) & 78.6 & 80.7 & 80.0 & 80.5 & 80.42 & 82.4 & 81.0 & 82.2 & 81.0 & 84.0 \\
\hline $\begin{array}{ll}\text { Boiling } & \text { water } \\
\text { shrinkage }(\%) & \end{array}$ & 2.11 & 1.72 & 1.42 & 1.30 & 1.98 & 1.69 & 1.87 & 1.78 & 1.96 & 1.70 \\
\hline Shrinkage force $(\mathrm{cN})$ & 3.43 & 3.11 & 1.63 & 1.60 & 3.74 & 3.90 & 2.41 & 2.58 & 3.17 & 3.10 \\
\hline
\end{tabular}

R. G. Ovejero and co-workers used non-linear regression methods to fit the experimental results to the three kinetics models of dying kinetics of poly(tri-methylene terephthalate (PTT) yarn with C.I. Disperse Red 82. They considered that this model adaptation was correct and relatively good fit was obtained due to that regression coefficient was higher than
0.90 in all case [17].

Yildirim K. also used regression-based mathematical model for prediction seam opening behavior of woven upholstery fabrics. He used this model for prediction seam opening behavior of woven fabric according to fabric properties with respect to test condition carried out under 
static and dynamic loading. They concluded that $R^{2}$ which was 0,90 and $r$ which was 0,96 values showed that the equations are well-suited to predicting seam opening behavior of woven fabric [18].

In the present study, the effect of first heater temperature, $\mathrm{D} / \mathrm{Y}$ ratio and draw ratio on boiling water shrinkage, shrinkage force, crimp stability and crimp contraction of textured PET yarn has been examined. The ability of regression-based model to predict yarn properties from production parameters was investigated in this study too.

\section{MATERIAL AND METHOD}

\section{A. Materials}

167 dtex, 96 filaments, semi-dull, POY PET yarn was draw-textured on the lab type Barmag AFK-M texturing machine with two heaters. Process speed was $650 \mathrm{~m} / \mathrm{min}$. The first heater length was $2.5 \mathrm{~m}$. Second heater length and temperature were $1.25 \mathrm{~m}$ and $165^{\circ} \mathrm{C}$, respectively. Disk-type friction texturing unit was used. The disk configuration was $1+6+1$. The disk material was ceramic and the disk thickness was $9 \mathrm{~mm}$

\section{B. Methods}

The simultaneous draw texturing process was carried out. All processing parameters were kept constant except first heater temperature, $\mathrm{D} / \mathrm{Y}$ ratio and draw ratio. The first heater temperatures were $150^{\circ} \mathrm{C}, 190^{\circ} \mathrm{C}$ and $230^{\circ} \mathrm{C}$. The. D/Y values were $1.5,2.0$, and 2.5 and the draw ratios were 1.55 , 1.60 and 1.65

\section{Measurements}

\section{1) Crimp properties of the yarn}

Crimp stability and crimp contraction tests were performed according to DIN 53840 standards by using Textechno Texturmat ME. Five specimens have been used for each samples.

Shrinkage force test was done using Textechno Dynafil ME. Dynafil ME was arranged for test as following: The applied pre-load was $13 \mathrm{cN}$, the heater temperature was 250 0C. The shrinkage force test was done at $90 \mathrm{~m} / \mathrm{min}$ testing speed. The yarn length was $50 \mathrm{~m}$.

\section{2) Boiling water shrinkage of the yarn}

Boiling water shrinkage test was carried out according to DIN 53866. Six specimens have been used for each samples. A tensioning weight of $0.125 \mathrm{cN} /$ tex was applied to the yarn, which was $I \mathrm{~m}$ in length, and a hank was formed. The first length in this condition was recorded as $I_{1}$, and then the load was removed. The yarn was wetted in a soap solution ( $I \mathrm{~g}$ of soap per $I_{1}$ of water) and left in the solution at $100^{\circ} \mathrm{C}$ for 15 min and then dried for one hour at $60^{\circ} \mathrm{C}$, after which the yarn was hung for $I \mathrm{~h}$ on the device. Then the same weight was applied to the yarn, and the length was recorded as $I_{2}$. Boiling water shrinkage was calculated from Eq. (3):

$$
\text { Boiling water shrinkage }(\%)=\left[\left(I_{1}-I_{2}\right) / I_{1}\right] \times 100
$$

\section{Mathematical Model}

In order to compute coefficients of the regression-based model with respect to selected production parameters, the yarns were textured with 27 different combinations and then were tested. All of the test results for these four yarn properties at different production parameters were used in the regression analysis. The advantage of using this model is to take into account the interaction effects in addition to the individual production parameters.

The regression-based mathematical model is similar to a completely randomized variance analysis model. The reason for establishing this type of model is to take into account the effects of both selected production parameters and their interactions. The model equation used in the study is

$$
\begin{aligned}
& \left.Y i=a_{i}+b_{i} \times(F H T)+c_{i} \times(D Y)+d_{i} \times / F H T \times D Y\right)+ \\
& e_{i} \times(D R)+f_{i} \times(F H T \times D R)+g_{i} \times(D Y \times D R)+ \\
& h_{i} \times(F H T \times D Y \times D R)
\end{aligned}
$$

where, $Y_{i}$ are the yarn properties $(i=1$, crimp stability, $i=2$, crimp contraction, $i=3$, shrinkage force, $i=4$, boiling water shrinkage), $a_{i}, b_{i}, c_{i}, d_{i}, e_{i}, f_{i}, g_{i}$ and $h_{i}$ are coefficients, and FHT (first heater temperature), $D Y(D / Y)$ and $D R$ (Draw ratio) are texturing process parameters. All coefficients were found based on a non-linear regression method in terms of the established equation by using the SPSS version 12 statistical program using the Levenberg-Marquardtmethod. Using these equation computer program were written by using $\mathrm{C}++$ (version 6.0).

\section{RESULTS AND DISCUSSION}

The non-linear regression equations relating textured yarn crimp stability, crimp contraction, shrinkage force and boiling water shrinkage, and texturing production parameters are given as follows:

Boiling water shrinkage $=-12.41708334+0.093702778 \times$ $F H T+7.669194437 \times D Y-0.052025000 \times F H T \times D Y+$ $11.679999994 \times D R-0.070666667 \times F H T \times D R-$ $4.880833329 \times D Y \times D R+0.032250000 \times F H T \times D Y \times D R$

Shrinkage force $=-56.02423607+0.219178241 \times F H T+$ $1.675578681 \times D Y-0.007340278 \times F H T \times D Y+$ $47.691435152 \times D R-0.186875000 \times F H T \times D R-$ $1.913194431 \times D Y \times D R+0.007291667 \times F H T \times D Y \times D R$

Crimp contraction $=-234.6944723+1.388652778 \times F H T+$ $125.50825003 \times D Y-0.675741667 \times F H T \times D Y+$ $131.89694447 \times D R-0.753083333 \times F H T \times D R$ $-75.88750002 \times D Y \times D R+0.410250000 \times F H T \times D Y \times D R$

Crimp stability $=29.951231506+0.227119444 \times F H T+$ $44.248166653 \times D Y-0.261183333 \times F H T \times D Y+$ $29.359444424 \times D R-0.117166667 \times F H T \times D R-$ $31.04083333 \times D Y \times D R+0.172250000 \times F H T \times D Y \times D R$

The computer code of the program is based on calculation 
of unknown yarn properties which are dependent variables of known production parameters which are independent variables of the model, as given in Eq. (5)-Eq. (8). Axes of the solution space are first heater temperature, D/Y and Draw ratio while surfaces in the space belong to the yarn properties. If the surfaces generate a closed volume in the space, any point in the closed volume is a solution for the question. The actual results and their standard deviations were given in Table I. These values were obtained from the samples of textured yarn, which were tested in the laboratory by using proper test devices. These values were used to calculate model coefficients by using non-linear regression analysis with respect to model equation.

The $R^{2}$ of the non-linear regression equations relating textured yarn crimp stability, crimp contraction, shrinkage force and boiling water shrinkage properties were change in terms of yarn properties type. The $R^{2}$ of the non-linear regression equations for crimp stability was 0.68 , for crimp contraction was 0.96 for shrinkage force was 0.99 and for boiling water shrinkage was 0.88 . As our model includes the effects of interactions of factors, the correlation coefficients between predicted and measured values are very good. Except crimp contraction properties, the rest of three properties can be predicted by using this model due to high value of $R^{2}$.

With the help of a regression-based model, we can predict four yarn properties easily and accurately. The ability of the model to estimate the properties of textured PET yarn was tested and all measured values and predicted values given in the Table II. The correlation coefficient $(r)$ was 0.83 for crimp stability, 0.98 for crimp contraction, 0.97 for shrinkage force and 0.90 for boiling water shrinkage. Higher correlation coefficient ( $r$ ) imply us that the result obtained from computer program by using this model can be acceptable as reliable for crimp contraction, boiling water shrinkage and shrinkage force properties of textured PET yarn, but for crimp stability properties there was a inconvenience for reliability of estimation. In order to increase level of accuracy and reliability of the equations, more samples produced under more different production conditions for calculation coefficients of model equation by non-linear regression analysis.

\section{CONCLUSION}

$R^{2}$ values for curves fitted to model equations have been observed to be highly reliable for crimp contraction and shrinkage force being about 0.98. Also the correlation coefficients between actual and predicted values for shrinkage force, crimp contraction and boiling water shrinkage were high being about $0.90 . R^{2}$ and $\mathrm{r}$ show that the equations are well-suited to predicting textured yarn properties for selected production parameters. This study was limited in that only three texturing parameters of PET yarns were adopted. The yarn properties could be predicted if the other factors are constant. In order to increase level of accuracy and reliability of the equations, it is very important to take into account other texturing parameters.

\section{REFERENCES}

[1] A. Demir and H. M. Behery, Synthetic Filament Yarn Texturing Technology, Prentice Hall, New Jersey, pp. 56-100, 1997.

[2] J. W. S. Hearl, L. Hollick, and D. K. Wilson, Yarn Texturing Technology, Woodhead Pub., Cambridge, pp. 86-132, 2001.

[3] T. Egambaram, E. M. Afify, and A. E. Shiekh, "Heat transfer in false-twist texturing," Textile Research Journal, vol. 44, no. 10, pp. 803-812, 1974.

[4] S. Ghosh and J. Wolhar, "The influence of some machine-setting variables on the properties of yarns in the friction-twist-draw-texturing process," Textile Res. J. Textile Research Journal, vol. 6, pp. 373-383, 1981.

[5] V. B. Gupta, D. B. Gupta, and S. C. Mittal, "The mechanical properties of textured polyethylene terepthalate yarn," Textile Research Journal, vol. 8, pp. 446-453, 1978

[6] J. M. Schultz, "Thermomechanical processing: Structure and properties in structure formation," in Polymeric Fibers, D. R. Salem, Ed., Carl Hanser Verlag: Munich, pp. 425-454, 2001.

[7] K., Yıldırım, Ş. Altun, and Y. Ulcay, "The effect of first heater temperature on the properties of false-twist textured poly (ethylene terapthalate) yarn," Tekstil ve Konfeksiyon, vol. 4, no. 19, p. 286, 2009.

[8] J. J. Thwaites, "The mechanics of friction twisting reassessed, Part II: Tension and torque generation in the disc spindle," J. Text. Inst., vol. 3, pp. 157-170, 1985 .

[9] S. K. Pal, R. S. Ganhi, and V. K. Kothari, "Draw texturing of microfiber polyester yarn," Textile Research Journal, vol. 12, pp. 770-776, 1996.

[10] A. W. Salamon and K. J. Fielder, "Practical use of differential calorimetry for plastics," in Handbook of Plastics Analysis, H. Lobo, J. V. Bonilla, Eds., Marcel Dekker: New York, pp. 79-109, 2003.

[11] K. Yildirim, S. Altun, and Y. Ulcay, "Relationship between yarn properties and process parameters in false-twist textured yarn," Journal of Engineered Fibers and Fabrics, vol. 4, no. 2, pp. 26-32, 2009.

[12] K. Yildırım, Y. Ulcay, and O. Kopmaz, "Forming regression based mathematical model to predict pet poy yarn properties in case of changing production parameters," Textile Research Journal, vol. 80, no. 5, p. 411, 2010.

[13] A. Majumdar, P. K. Majumdar, and B. Sarkar, "Application of linear regression, artificial neural network and neuro-fuzzy algorithms to predict the breaking elongation of rotor-spun yarns," Indian Journal of Fiber \& Textile Research, vol. 30, no. 19, 2003.

[14] J. Carey, M. Munro, and A. Fahim, "Regression-based model for elastic constants of 2D braided/woven open mesh angle ply composites," Polymer Composition, vol. 26, no. 152, 2005.

[15] V. Sular and A. Okur, "Objective evaluation of fabric handle by simple measurement methods," Textile Research Journal, vol. 78, no. 10, p. 856, 2008.

[16] C. H. Park, Y. Jun, T. J. Kang, and J. H. Kim, "Development of a tool to measure the pressure comfort of a cap (II) by the analysis of correlation between objective pressure and subjective wearing sensation," Textile Research Journal, vol. 77, no. 7, p. 520, 2007.

[17] R. G. Ovejero, J. R. Sanchez, J. B. Ovejero, J. Valldeperas, and M. J. Lis, "Kinetic and diffusional approach to the dyeing behavior of the polyester PTT," Textile Research Journal, vol. 77, no. 10, p. 804, 2007.

[18] K. Yıldırım, "Predicting seam opening behavior of seat woven fabrics," Textile Research Journal, vol. 80, no. 5, p. 472, 2010.

[19] K. Yildirim, "Determination of degree of production parameters influences to the cristallinity ratio on the pet yarn," $\mathrm{PhD}$ thesis, Department of Textile Engineering, Uludağ University, 2007.

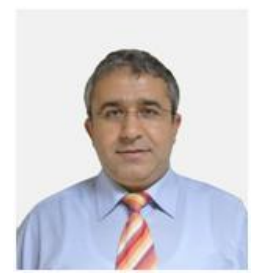

Kenan Yildirim is an associate professor at the Fiber and Polymer Engineering Department of Bursa Technical University, Turkey. $\mathrm{He}$ is currently holding visiting lecturer position at International Turkmen-Turk University at Ashgabat, Turkmenistan, which is supported by Ministry of Education of Turkey (MEB) and Turkish Cooperation and Coordination Agency (TIKA). He holds a $\mathrm{PhD}$ degree in textile engineering from University of Uludag. He conducted his masters studies at Textile Engineering Department of Uludag University. His research interests include knitting technology and machines, technical textiles, polymer characterization, pet yarn synthetic yarn technology, developing new test method and device for textile materials in the scope of TS EN ISO/ IEC 17025 and TS EN ISO 17020, accreditation laboratory according to TS EN ISO/ IEC 17025 and inspection according to EN ISO 17020, carry out quality control tests for textile and polymeric 
materials, Analyze and design circler knitted and warp knitted fabrics, Maintance and repairing of test device, determination of the source of the faults on the textile materials, measurement and evaluation of noise in the environment, measurement and evaluation noise dose on the worker in factory. His work has also appeared in many journals like textile research journal, coloration technology, e-polymers and in the proceedings of numerous international and national conferences.

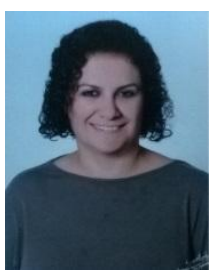

Suna Cetin is an assistant professor at the Industrial Engineering Department of University of Kırıkkale, Turkey. She is currently holding visiting lecturer position at International Turkmen-Turk University at Ashgabat, Turkmenistan, which is supported by Ministry of Education of Turkey (MEB) and Turkish Cooperation and Coordination Agency (TIKA). She holds a $\mathrm{PhD}$ degree in Industrial Engineering from Gazi University. She conducted his masters studies at Industrial Engineering Department of Kırıkkale University. Her research interests include project management, vehicle routing problems, mathematical modeling. Her work has also appeared in Journal of The Faculty of Engineering and Architecture of Gazi University and in the proceedings of numerous international and national conferences.

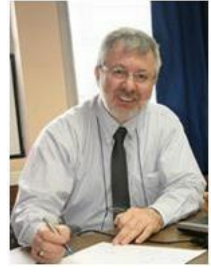

Yusuf Ulcay is a professor at the Te Engineering Department of Uludag University, Turkey. He holds a $\mathrm{PhD}$ degree in textile engineering from Maryland Üniversitesy. He conducted his masters studies at Textile Engineering Department of Maryland Üniversitesy. His research interests include textile materials, technical textiles, medical textiles, composite materials, statistics, PET yarn, Synthetic yarn technology. His work has also appeared in many journals like textile research journal, coloration technology, e-polymers and in the proceedings of numerous international and national conferences. 